\title{
Two Level Fuzzy Based Energy Management System with Integrated Solar and Wind Based Generating System in Smart Grid Environment
}

\author{
A.Albert Martin Ruban ${ }^{\$ 1}$, N.Hemavathi*2, N.Rajeswari ${ }^{*}{ }^{3}$ K. Selvakumar ${ }^{\sharp 4}$ \\ ${ }^{\$}$ Research Scholar, Manonmaniam Sundaranar University, Tirunelveli, India \& \\ Associate Professor, Kings College of Engineering, Pudukkottai, India \\ 11albertrubankings@gmail.com \\ *Assistant Professor, Kings College of Engineering, Pudukkottai, India \\ 2nuhemasen@gmail.com \\ rajeswarikings@gmail.com \\ \#Associate Professor, Annamalai University, Chidambaram, India \\ ${ }^{4}$ kskaucse@yahoo.co.in
}

\begin{abstract}
As conventional energy sources are depleting, renewable energy sources play a vital role. The renewable energy sources such as solar and wind based power production is the appropriate solution due to its surplus availability. However, the uncertainty in the availability of these resources due to environmental factors results in uncertainty in power production which ought to be dealt seriously. The power produced from these resources is connected through grid to the loads. If the produced power exceeds the total demand by the loads, then excess power can be sold to utility. Hence, it is mandate to produce maximum possible power from these renewable resources irrespective of the environment influencing factors. To achieve this, a novel two level fuzzy based energy prediction system is proposed. The proposal considers the influencing parameters for both solar and wind energy based power production. Accordingly, the first level fuzzy based controller which is designed to produce maximum power is tuned to obtain maximum power from these resources. The total power generated from the integrated system is compared with that of the total demand. If the demand is lesser, then excess power is used to charge the battery and hence, the State of Charge of the battery can be increased up to $95 \%$. Using second level fuzzy logic controller, the excess power will be predicted which will be sold to the utility. The algorithm is implemented in Matlab. The proposed methodology exhibit the efficacy of the proposal.
\end{abstract}

KEYWORD - Smart Grid, FLC, Solar PV, Wind, Units sold

\section{INTRODUCTION}

Due to depletion of conventional energy sources and environmental hazards, renewable energy sources are the synergetic and eco friendly energy solution. Among these renewable energy sources ,the most promising power generation technologies are solar and wind energy as it is available in abundance. However, there is an uncertainty in power generation due to variation in geographic and seasonal climatic conditions that affect the solar and wind energy output. Hence, a backup power system is needed for reliable and sustainable power generation and is achieved through batteries. Further, the dynamic interaction between the load demand and the integrated renewable energy sources lead to stability and power quality problems that are not very common in conventional power systems. Therefore, managing the flow of energy throughout the hybrid system is essential to ensure the continuous energy flow [1][2].

Several research works are proposed in the literature. The energy management in stand-alone hybrid power systems is proposed [3]. Maximum Power Point (MPP) is achieved through neural network whereas fuzzy logic controller is used to manage charging and discharging of batteries for performance optimization. However, the system did not consider all the influencing parameters for hybrid energy based power production. A fuzzy logic based controller for the voltage control of the designed hybrid system is proposed and compared with a classical PI controller for performance validation [4]. Nevertheless, the system is unpredictable as it considers wind speed alone rather than all the influencing parameters. An adaptive neuro-fuzzy inference system with wind velocity and Reynold's number as input parameters for wind power extraction is proposed [5]. Here, Reynold's number depends on free stream wind velocity, dynamic viscosity and chord length. However, all the influencing parameters for wind power extraction are not considered. 
Fuzzy logic based prediction of power from wind energy is proposed [6]. The considered parameters are turbine swept area, air density, wind speed and power coefficient as a function of pitch angle and blade tip speed. A hybrid neuro-fuzzy based wind power prediction system for optimum operation of a power system is proposed [7].Air temperature, wind speed, air density and air pressure are measured and transmitted using Wireless Sensor Network (WSN). The optimal number of fuzzy rules is decided by Fuzzy C-Means (FCM). However, these works concentrated on the power production with wind energy alone and further; the energy management system is not dealt.

The time series models for predicting the power of a wind farm at different time scales is presented [8]. Out of five data mining algorithms, support vector machine regression algorithm and Multi layer perceptron algorithm provides accurate predictions of wind power and wind speed. However, the power cannot be accurately determined as all the influencing parameters are not considered. The upcoming wind speed is forecasted using fuzzy logic and is based on the stochastic characteristics of wind speed of previous years [9]. On the other hand, wind speed alone is predicted.

The fuzzy based optimal power delivery under frequent and unpredictable load variation is proposed[10]. Online energy management between four energy sources namely PV panels, wind turbine, battery storage and Fuel Cell is proposed to optimize the active power flow between system power sources for different modes of operation and to maintain the battery State of Charge $(\mathrm{SoC})$ at a reasonable level [11]. Nonetheless, these works do not consider the influencing parameters for either solar or wind energy based power production and hence, the energy management system is not efficient.

The performance of the PV module depends on shading and soiling since the cells receive less irradiation [12]. The factors such as temperature, MPPT (Maximum Power Point Tracking) and energy conversion efficiency influencing PV panel output are proposed [13]. However, these works do not consider all the influencing factors for PV panel power production.

In all the above works, either wind energy or solar based power production is predicted. If both wind and solar are considered, then energy management system is designed and implemented without taking into account all the influencing parameters for the power production from these renewable energy sources. To alleviate these issues, a novel two level fuzzy based energy management system for hybrid power production from PV and wind energy is proposed. The system considers temperature, relative humidity, soiling, shading and irradiation for PV panel output whereas wind speed, wind direction, elevation, temperature and relative humidity for wind energy based power production. The proposed system is elucidated in the following section.

\section{PROPOSED SYSTEM}

The system considers the influencing parameters of output power from PV panel such as Temperature, Relative Humidity, Shading, Irradiation and Soiling as input parameters to decide upon the output power. Similarly, the parameters namely Wind Direction, Relative Humidity, Temperature, Wind Speed and Elevation are considered as inputs to obtain the output power from the wind turbine. Due to climatic and other influencing factors, the output power produced from PV and wind turbines are fluctuating and it is maintained at maximum power by first level fuzzy and DC-DC converters. The Output from solar and wind energy sources are computed and it is compared with the actual demand from load side. If the power in the supply side exceeds the power required by the load, then excess power is used to charge the battery. The State of Charge $(\mathrm{SoC})$ of the battery is increased from $50 \%$ to $95 \%$. The life time of the battery is enhanced by keeping the SoC so that it will not reduce below minimum limit (50\%) and will not exceed above maximum limit $(95 \%)$. If the power produced from solar and wind still exceeds, then excess power is sold to the utility.

To increase the selling units of power to the utility, two level fuzzy based approach as shown in fig. 1 is used. The power production from solar and wind power is predicted using first level fuzzy. Based on the prediction, the maximum possible power from these resources is obtained by controlling the performance of DC-DC converters. The output power from solar and wind generators are fed to DC grid. The demand of the connected load is fed as Input. The Energy Management System (EMS) will compare the available power $\left(\mathrm{P}_{\mathrm{S}}\right)$ with that of demand $\left(\mathrm{P}_{\mathrm{D}}\right)$. If the available power exceeds, then battery is charged or else it is discharged. 


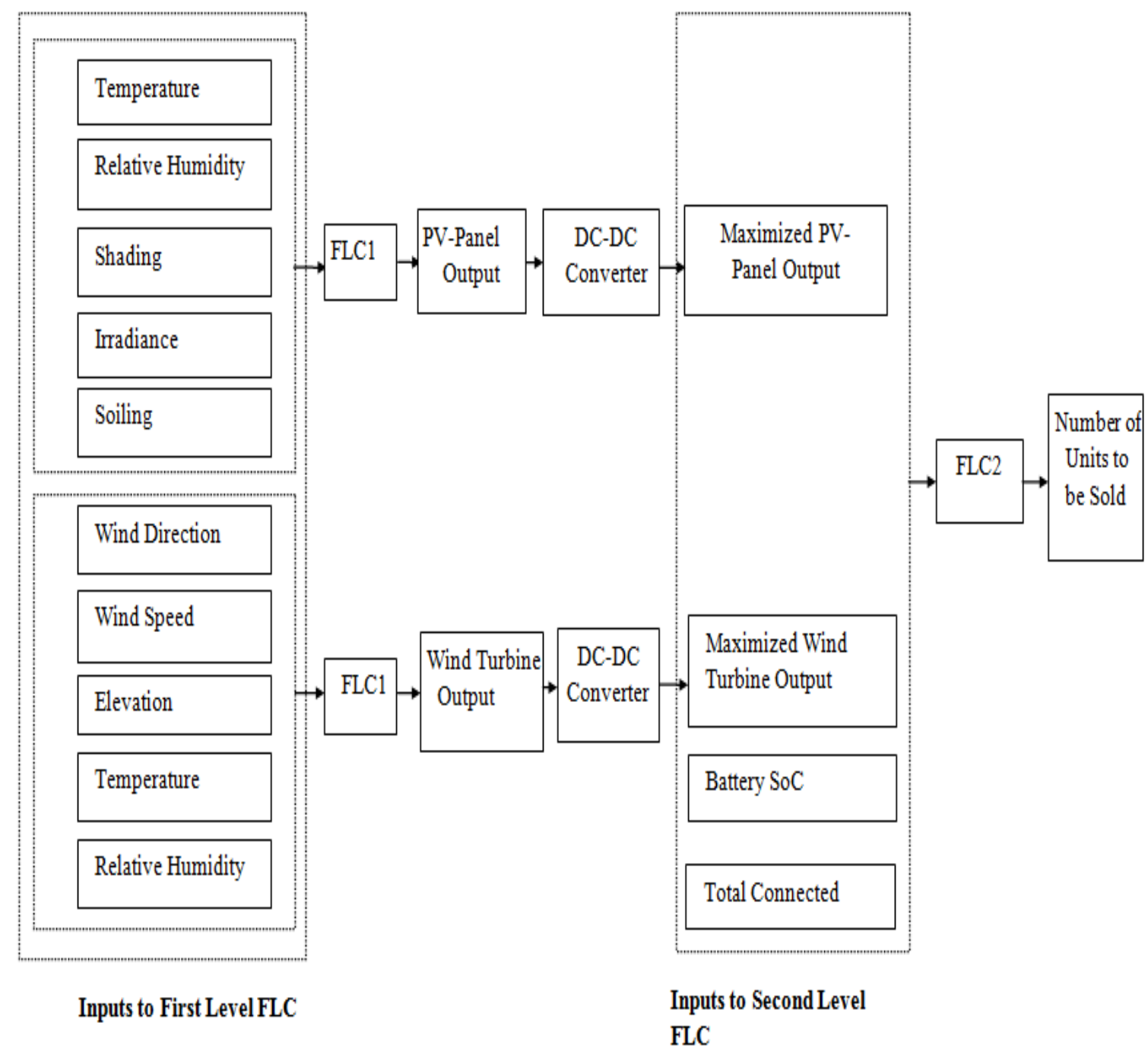

Fig.1 Two Level Fuzzy Based Energy Management System

The second level fuzzy is called to estimate the number of units to be sold to the utility based on maximized PV panel power output and wind turbine output, battery SoC and total connected load. The flowchart of the proposed system is shown in fig.2.

\section{IMPLEMENTATION}

The algorithm is implemented in Matlab. Fig.3 shows the general FLC structure with Fuzzifier, Inference Engine, Fuzzy Rule Base (FRB) and Defuzzifier. The crisp input is fuzzified through the predefined membership functions. The Fuzzy Rule Base is a set of rules which is applied to the fuzzified input. The output of the inference engine is converted to crisp output by the process of defuzzification. The method of defuzzification used is the 'Centroid' method. In Two-Level fuzzy, any of the outputs obtained in first level fuzzy is fed as input to the second level fuzzy. In this proposal, the first level fuzzy output of PV panel output and wind turbine output are fed as inputs to the second level fuzzy based energy management system. 


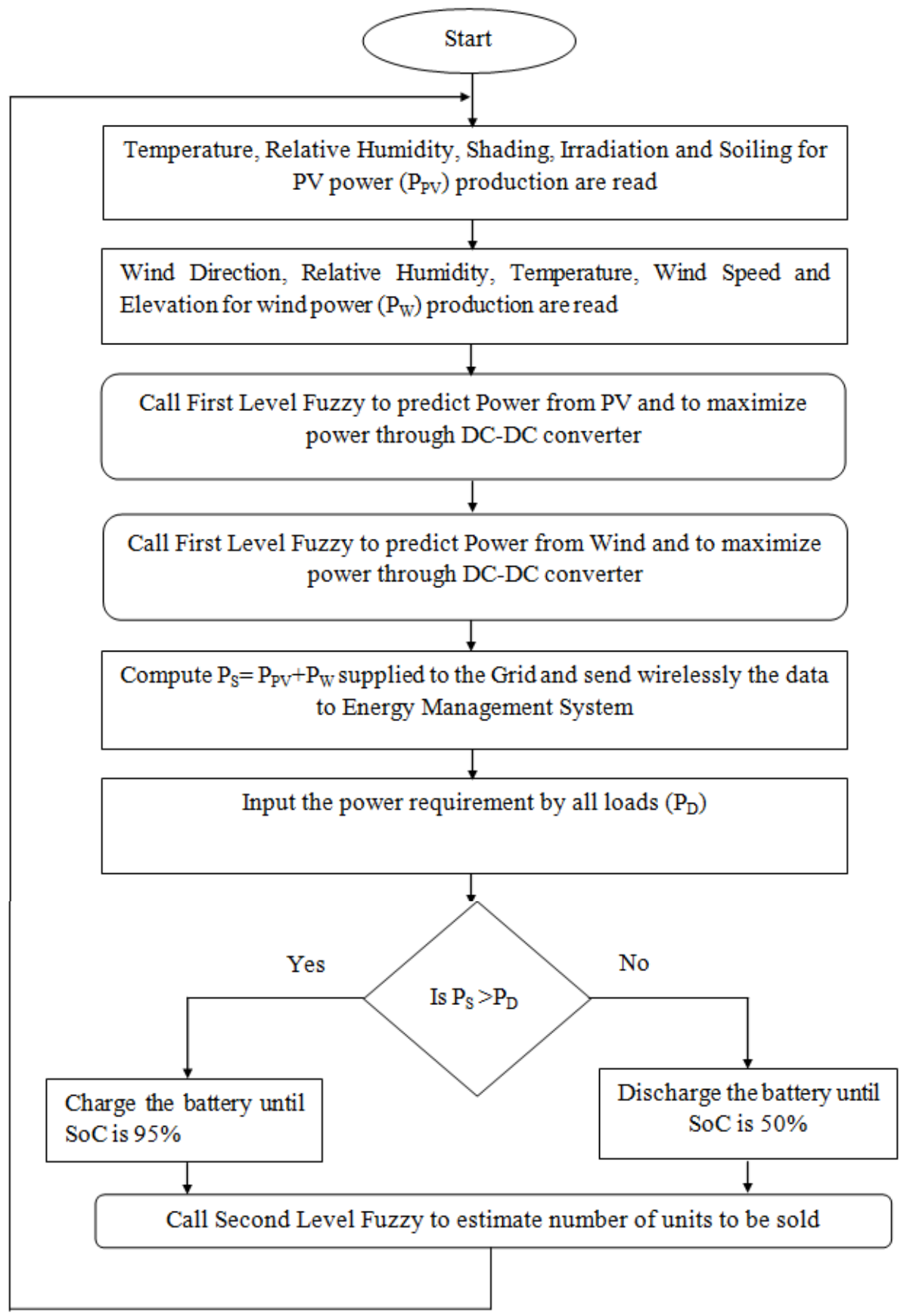

Fig.2. Flow Chart

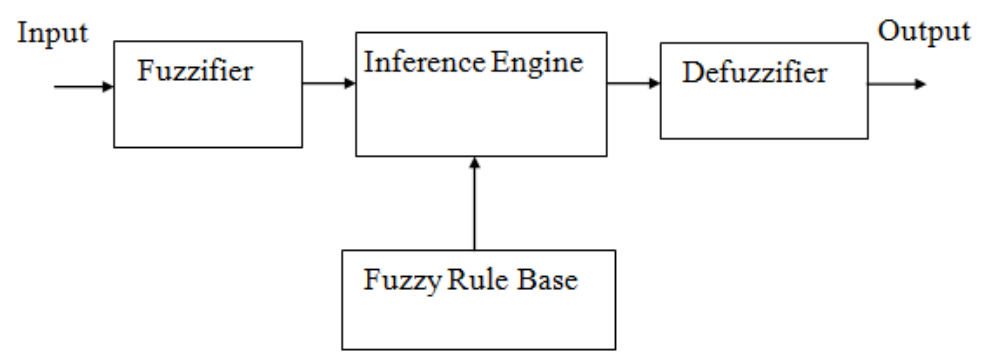

Fig.3. FLC structure

The input and output term sets along with membership functions for first level fuzzy for PV panel output and wind turbine output are presented in Tables 1-4 respectively. The Fuzzy Rule Base of 243 rules $(3 \times 3 \times 3 \times 3 \times 3)$ for PV panel power output and 243 rules $(3 \times 3 \times 3 \times 3 \times 3)$ for wind turbine output are formed in first level fuzzy. The input and output term sets for second level fuzzy based Energy Management System is portrayed in Tables 5and 6 respectively. The outputs of first level fuzzy along with the inputs namely SoC of battery and the connected 
load are fed to second level fuzzy and the FRB has $225(5 \times 5 \times 3 \times 3)$ rules. In this proposal, the first level fuzzy is splitted into two and is implemented with 486 (i.e 243+243) rules. If it is implemented with all the inputs for PV and Wind turbine power together, then 6561 (i.e. $3 \times 3 \times 3 \times 3 \times 3 \times 3 \times 3 \times 3$ ) rules are mandate. This clearly elucidates the efficacy of the proposal with reduced computational complexity.

Table.1. Input parameters term sets with membership functions for PV panel output

\begin{tabular}{|l|l|l|l|}
\hline Input Parameters & Term Sets & Membership functions & Limits \\
\hline \multirow{4}{*}{ Temperature in ${ }^{\circ} \mathrm{C}$} & Low & Trapezoidal & $\{-10 ; 0 ; 10 ; 20\}$ \\
\cline { 2 - 4 } & Middle & Triangular & $\{10 ; 25 ; 40\}$ \\
\cline { 2 - 4 } & High & Trapezoidal & $\{30 ; 40 ; 60 ; 70\}$ \\
\hline \multirow{5}{*}{ Relative Humidity in \% } & Low & Trapezoidal & $\{-10 ; 0 ; 20 ; 30\}$ \\
\cline { 2 - 4 } & Medium & Triangular & $\{20 ; 35 ; 50\}$ \\
\cline { 2 - 4 } & High & Trapezoidal & $\{40 ; 50 ; 80 ; 90\}$ \\
\hline \multirow{5}{*}{ Irradiance in $\mathrm{kW} / \mathrm{m}^{2}$} & Little & Trapezoidal & $\{-10 ; 0 ; 20 ; 30\}$ \\
\cline { 2 - 4 } & Moderate & Trapezoidal & $\{20 ; 30 ; 60 ; 70\}$ \\
\cline { 2 - 4 } & More & Trapezoidal & $\{60 ; 70 ; 100 ; 110\}$ \\
\hline & Small & Trapezoidal & $\{-1 ; 0 ; 2 ; 3\}$ \\
\cline { 2 - 4 } & Medium & Triangular & $\{2 ; 4 ; 6\}$ \\
\cline { 2 - 4 } & Large & Trapezoidal & $\{5 ; 6 ; 10 ; 12\}$ \\
\hline \multirow{5}{*}{ Soiling in $\%$} & Little & Trapezoidal & $\{-2 ; 0 ; 6 ; 8\}$ \\
\cline { 2 - 4 } & Medium & Triangular & $\{6 ; 10 ; 14\}$ \\
\cline { 2 - 4 } & High & Trapezoidal & $\{12 ; 14 ; 20 ; 22\}$ \\
\hline
\end{tabular}

Table.2.. Output parameters term sets with membership functions for PV panel output

\begin{tabular}{|l|l|l|l|}
\hline Output Parameters & Term Sets & Membership functions & Limits \\
\hline \multirow{5}{*}{ PV Panel Output in W } & Very Low & Trapezoidal & $\{-80 ; 0 ; 240 ; 320\}$ \\
\cline { 2 - 4 } & Low & Triangular & $\{240 ; 320 ; 400\}$ \\
\cline { 2 - 4 } & Medium & Triangular & $\{320 ; 400 ; 480\}$ \\
\cline { 2 - 4 } & High & Triangular & $\{400 ; 480 ; 560\}$ \\
\cline { 2 - 4 } & Very High & Trapezoidal & $\{480 ; 560 ; 800 ; 920\}$ \\
\hline
\end{tabular}

Table.3. Input parameters term sets with membership functions for wind turbine

\begin{tabular}{|l|l|l|l|}
\hline Input Parameters & Term Sets & Membership functions & Limits \\
\hline \multirow{4}{*}{ Wind Direction in } & Little & Trapezoidal & $\{-50 ; 0 ; 100 ; 150\}$ \\
\cline { 2 - 4 } & Moderate & Triangular & $\{100 ; 175 ; 250\}$ \\
\cline { 2 - 4 } & More & Trapezoidal & $\{200 ; 250 ; 350 ; 360\}$ \\
\hline \multirow{4}{*}{ Wind Speed in m/s } & Small & Trapezoidal & $\{-3 ; 0 ; 3 ; 6\}$ \\
\cline { 2 - 4 } & Medium & Triangular & $\{3 ; 6 ; 9\}$ \\
\cline { 2 - 4 } & Large & Trapezoidal & $\{6 ; 9 ; 12 ; 15\}$ \\
\hline \multirow{4}{*}{ Temperature in $\circ \mathrm{C}$} & Low & Trapezoidal & $\{-200 ; 0 ; 400 ; 600\}$ \\
\cline { 2 - 4 } & Medium & Triangular & $\{400 ; 750 ; 1100\}$ \\
\cline { 2 - 4 } & High & Trapezoidal & $\{800 ; 1100 ; 1500 ; 1700\}$ \\
\cline { 2 - 4 } & Hoderate & Trapezoidal & $\{-10 ; 0 ; 10 ; 20\}$ \\
\hline \multirow{3}{*}{$\begin{array}{l}\text { Relative Humidity } \\
\text { in \% }\end{array}$} & Low & Triangular & $\{10 ; 25 ; 40\}$ \\
\cline { 2 - 4 } & Medium & Triangular & $\{30 ; 40 ; 60 ; 70\}$ \\
\cline { 2 - 4 } & High & Trapezoidal & $\{-10 ; 0 ; 20 ; 30\}$ \\
\hline
\end{tabular}


Table.4. Output parameters term sets with membership functions for wind turbine

\begin{tabular}{|l|l|l|l|}
\hline Output Parameters & Term Sets & Membership functions & Limits \\
\hline \multirow{4}{*}{$\begin{array}{l}\text { Wind } \\
\text { Generator Output in }\end{array}$} & Very Low & Trapezoidal & $\{-25 ; 0 ; 75 ; 100\}$ \\
\cline { 2 - 4 } & Low & Triangular & $\{75 ; 100 ; 125\}$ \\
\cline { 2 - 4 } & Medium & Triangular & $\{100 ; 125 ; 150\}$ \\
\cline { 2 - 4 } & High & Triangular & $\{125 ; 150 ; 175\}$ \\
\cline { 2 - 4 } & Very High & Trapezoidal & $\{150 ; 175 ; 250 ; 260\}$ \\
\hline
\end{tabular}

Table.5. Input parameters term sets with membership functions for energy management system

\begin{tabular}{|c|c|c|c|}
\hline Input Parameters & Term Sets & Membership functions & Limits \\
\hline \multirow{5}{*}{ PV Panel Output } & Very Low & Trapezoidal & $\left\{\begin{array}{llll}-80 & 0 & 240 & 320\end{array}\right.$ \\
\hline & Low & Triangular & $\{240320400\}$ \\
\hline & Medium & Triangular & $\{320400480\}$ \\
\hline & High & Triangular & $\{400480560\}$ \\
\hline & Very High & Trapezoidal & $\{480560800880\}$ \\
\hline \multirow{5}{*}{ Wind Turbine Output } & Very Low & Trapezoidal & $\left\{\begin{array}{llll}-25 & 0 & 75 & 100\end{array}\right.$ \\
\hline & Low & Triangular & $\left\{\begin{array}{llll}75 & 100 & 125\end{array}\right.$ \\
\hline & Medium & Triangular & $\left\{\begin{array}{llll}100 & 125 & 150\end{array}\right.$ \\
\hline & High & Triangular & $\left\{\begin{array}{llll}125 & 150 & 175\end{array}\right.$ \\
\hline & Very High & Trapezoidal & $\left\{\begin{array}{lllll}150 & 175 & 250 & 275\end{array}\right.$ \\
\hline \multirow{3}{*}{ Battery SoC } & Low & Trapezoidal & $\left\{\begin{array}{lllll}-10 & 0 & 30 & 40\end{array}\right.$ \\
\hline & Medium & Triangular & $\{105090\}$ \\
\hline & High & Trapezoidal & $\left\{\begin{array}{lllll}60 & 70 & 100 & 110\end{array}\right.$ \\
\hline \multirow{3}{*}{ Connected Load } & Light & Trapezoidal & $\left\{\begin{array}{llll}-250 & 0 & 500 & 750\end{array}\right.$ \\
\hline & Moderate & Triangular & $\left\{\begin{array}{llll}500750 & 1000\end{array}\right.$ \\
\hline & Heavy & Trapezoidal & $\left\{\begin{array}{lllll}750 & 1000 & 1500 & 1750\end{array}\right.$ \\
\hline
\end{tabular}

Table .6. Output parameters term sets with membership functions for energy management system

\begin{tabular}{|c|c|c|c|}
\hline Output Parameters & Term Sets & Membership functions & Limits \\
\hline \multirow{7}{*}{ Number of units sold } & Very Low & Trapezoidal & $\left\{\begin{array}{llll}-10 & 0 & 20 & 30\end{array}\right.$ \\
\hline & Low & Triangular & $\{203040\}$ \\
\hline & Little Low & Triangular & $\{304050\}$ \\
\hline & Medium & Triangular & $\{405060\}$ \\
\hline & Little Medium & Triangular & $\left\{\begin{array}{llll}50 & 60 & 70\end{array}\right.$ \\
\hline & High & Triangular & $\{607080\}$ \\
\hline & Very High & Trapezoidal & $\left\{\begin{array}{llll}70 & 90100110\}\end{array}\right.$ \\
\hline
\end{tabular}

The input parameters such as temperature, relative humidity, shading, irradiation and soiling are given as input and the power produced by the PV panel is predicted. Accordingly, the switching devices of DC-DC converter are triggered and the average output voltage obtained in DC-DC converter is maintained at maximum level. The FRB corresponds to first level fuzzy for PV panel output is presented in Table 7.The snapshot of first level fuzzy logic based PV panel output is depicted in fig.4.

Similarly, the influencing parameters for power production from wind energy are considered as input and the wind power generated is predicted using FLC1. The actual power available is maximized by proper triggering of Gate pulses of controlled devices employed in DC-DC converters.

The snapshot of first level fuzzy based Wind turbine output is portrayed in fig.5. The system considers wind direction, wind speed, elevation, temperature and relative humidity as the input parameters to predict the output power from wind turbine. The FRB for Wind Turbine Power output is presented in Table 8. 


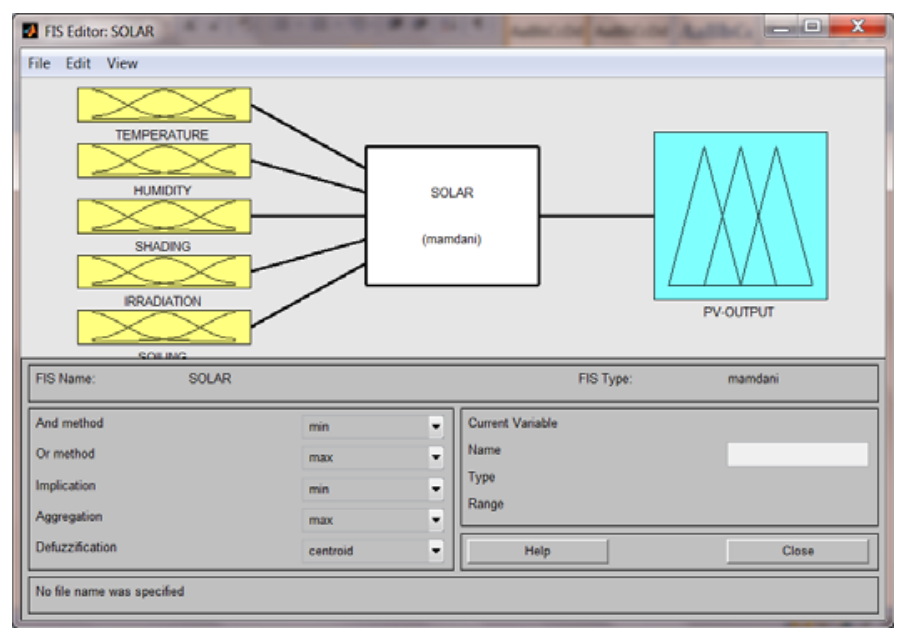

Fig.4. Snapshot of first level Fuzzy Logic Based PV power production

Table.7.FRB for PV panel output

\begin{tabular}{|c|c|c|c|c|c|c|}
\hline $\begin{array}{c}\text { Rule } \\
\text { No. }\end{array}$ & Temperature & $\begin{array}{l}\text { Relative } \\
\text { Humidity }\end{array}$ & Shading & Irradiation & Soiling & Output Power \\
\hline 1 & Low & Low & Little & Small & Little & High \\
\hline 2 & Low & Low & Little & Small & Medium & Medium \\
\hline 3 & Low & Low & Little & Small & More & Low \\
\hline 4 & Low & Low & Little & Medium & Little & High \\
\hline 5 & Low & Low & Little & Medium & Medium & Medium \\
\hline 6 & Low & Low & Little & Medium & More & Medium \\
\hline 7 & Low & Low & Little & Large & Little & High \\
\hline 8 & Low & Low & Little & Large & Medium & Medium \\
\hline 9 & Low & Low & Little & Large & More & Medium \\
\hline \multicolumn{7}{|l|}{. } \\
\hline 28 & Low & Medium & Little & Small & Little & Medium \\
\hline 29 & Low & Medium & Little & Small & Medium & Low \\
\hline 30 & Low & Medium & Little & Small & More & Very Low \\
\hline 31 & Low & Medium & Little & Medium & Little & High \\
\hline 32 & Low & Medium & Little & Medium & Medium & Medium \\
\hline 33 & Low & Medium & Little & Medium & More & Low \\
\hline 34 & Low & Medium & Little & Large & Little & High \\
\hline 35 & Low & Medium & Little & Large & Medium & Medium \\
\hline 36 & Low & Medium & Little & Large & More & Low \\
\hline 82 & Middle & Low & Little & Small & Little & Medium \\
\hline 83 & Middle & Low & Little & Small & Medium & Low \\
\hline 84 & Middle & Low & Little & Small & More & Low \\
\hline 85 & Middle & Low & Little & Medium & Little & High \\
\hline 86 & Middle & Low & Little & Medium & Medium & Medium \\
\hline 87 & Middle & Low & Little & Medium & More & Low \\
\hline 88 & Middle & Low & Little & Large & Little & Very High \\
\hline 89 & Middle & Low & Little & Large & Medium & High \\
\hline 90 & Middle & Low & Little & Large & More & Medium \\
\hline . & & & & & & \\
\hline 235 & High & High & More & Small & Little & Low \\
\hline 236 & High & High & More & Small & Medium & Very Low \\
\hline
\end{tabular}




\begin{tabular}{|l|l|l|l|l|l|l|}
\hline 237 & High & High & More & Small & More & Very Low \\
\hline 238 & High & High & More & Medium & Little & Low \\
\hline 239 & High & High & More & Medium & Medium & Very Low \\
\hline 240 & High & High & More & Medium & More & Very Low \\
\hline 241 & High & High & More & Large & Little & Low \\
\hline 242 & High & High & More & Large & Medium & Low \\
\hline 243 & High & High & More & Large & More & Very Low \\
\hline
\end{tabular}

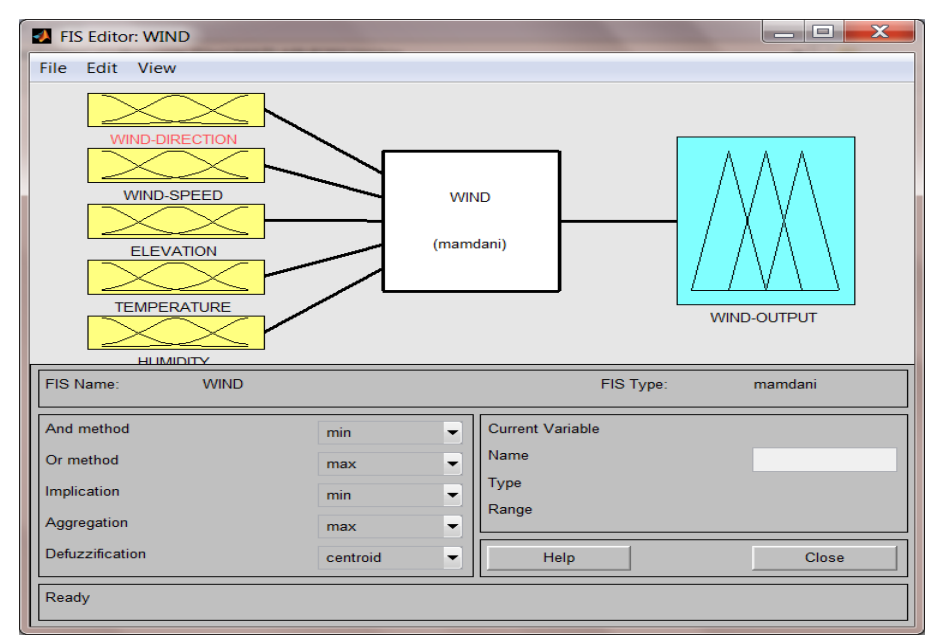

Fig.5. Snapshot of first level fuzzy logic based wind power production

Table.8. FRB for wind turbine output

\begin{tabular}{|c|c|c|c|c|c|c|}
\hline Rule No. & $\begin{array}{l}\text { Wind } \\
\text { Direction }\end{array}$ & $\begin{array}{l}\text { Wind } \\
\text { Speed }\end{array}$ & Elevation & Temperature & $\begin{array}{l}\text { Relative } \\
\text { Humidity }\end{array}$ & Output Power \\
\hline 1 & Little & Small & Low & Low & Low & Low \\
\hline 2 & Little & Small & Low & Low & Medium & Very Low \\
\hline 3 & Little & Small & Low & Low & High & Very Low \\
\hline 4 & Little & Small & Low & Moderate & Low & Low \\
\hline 5 & Little & Small & Low & Moderate & Medium & Very Low \\
\hline 6 & Little & Small & Low & Moderate & High & Very Low \\
\hline 7 & Little & Small & Low & High & Low & Low \\
\hline 8 & Little & Small & Low & High & Medium & Very Low \\
\hline 9 & Little & Small & Low & High & High & Very Low \\
\hline 28 & Little & Medium & Low & Low & Low & Low \\
\hline 29 & Little & Medium & Low & Low & Medium & Low \\
\hline 30 & Little & Medium & Low & Low & High & Very Low \\
\hline 31 & Little & Medium & Low & Moderate & Low & Low \\
\hline 32 & Little & Medium & Low & Moderate & Medium & Very Low \\
\hline 33 & Little & Medium & Low & Moderate & High & Very Low \\
\hline 34 & Little & Medium & Low & High & Low & Medium \\
\hline 35 & Little & Medium & Low & High & Medium & Low \\
\hline 36 & Little & Medium & Low & High & High & Low \\
\hline 154 & Moderate & Large & High & Low & Low & Medium \\
\hline 155 & Moderate & Large & High & Low & Medium & Low \\
\hline 156 & Moderate & Large & High & Low & High & Low \\
\hline 157 & Moderate & Large & High & Moderate & Low & High \\
\hline 158 & Moderate & Large & High & Moderate & Medium & Medium \\
\hline 159 & Moderate & Large & High & Moderate & High & Medium \\
\hline 160 & Moderate & Large & High & High & Low & Very High \\
\hline 161 & Moderate & Large & High & High & Medium & Very High \\
\hline 162 & Moderate & Large & High & High & High & High \\
\hline
\end{tabular}




\begin{tabular}{|l|l|l|l|l|l|l|}
\hline$\cdot$ & & & & & & \\
\hline 235 & More & Large & High & Low & Low & Medium \\
\hline 236 & More & Large & High & Low & Medium & Low \\
\hline 237 & More & Large & High & Low & High & Low \\
\hline 238 & More & Large & High & Moderate & Low & High \\
\hline 239 & More & Large & High & Moderate & Medium & Medium \\
\hline 240 & More & Large & High & Moderate & High & Low \\
\hline 241 & More & Large & High & High & Low & High \\
\hline 242 & More & Large & High & High & Medium & High \\
\hline 243 & More & Large & High & High & High & Medium \\
\hline
\end{tabular}

Then the maximized output from PV panel and wind turbine is fed as input to the second level fuzzy based Energy Management System in addition to SoC of the battery and total connected load. The energy management system implemented as second level fuzzy is shown in fig.6. The EMS considers PV panel output, wind turbine output after DC-DC conversion, battery and connected load as input parameters to decide upon the number of units to be sold. The FRB corresponds to second level fuzzy based EMS is portrayed in Table 9.

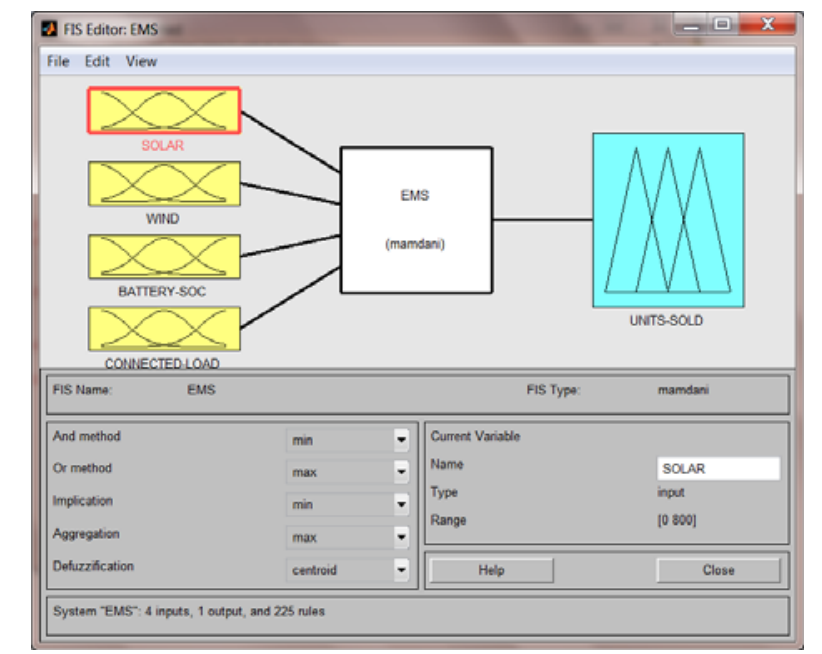

Fig.6. Snapshot of second level Fuzzy to predict number of units to be sold

Table.9. Second level fuzzy based energy management system

\begin{tabular}{|l|l|l|l|l|l|}
\hline Rule No. & PV Output & $\begin{array}{l}\text { Wind Turbine } \\
\text { Output }\end{array}$ & Battery SoC & Connected Load & $\begin{array}{l}\text { No. of Units } \\
\text { to be Sold }\end{array}$ \\
\hline 1 & Very Low & Very Low & Low & Light & Very Low \\
\hline 2 & Very Low & Very Low & Low & Moderate & Very Low \\
\hline 3 & Very Low & Very Low & Low & Heavy & Very Low \\
\hline 4 & Very Low & Very Low & Medium & Light & Very Low \\
\hline 5 & Very Low & Very Low & Medium & Moderate & Very Low \\
\hline 6 & Very Low & Very Low & Medium & Heavy & Very Low \\
\hline 7 & Very Low & Very Low & High & Light & Very Low \\
\hline 8 & Very Low & Very Low & High & Moderate & Very Low \\
\hline 9 & Very Low & Very Low & High & Heavy & Very Low \\
\hline. & & & & & \\
\hline 181 & Very High & Very Low & Low & Light & Low \\
\hline 182 & Very High & Very Low & Low & Moderate & Low \\
\hline 183 & Very High & Very Low & Low & Heavy & Little Low \\
\hline 184 & Very High & Very Low & Medium & Light & Low \\
\hline 185 & Very High & Very Low & Medium & Moderate & Little Low \\
\hline 186 & Very High & Very Low & Medium & Heavy & Little Low \\
\hline 187 & Very High & Very Low & High & Light & Low \\
\hline 188 & Very High & Very Low & High & Moderate & Little Low \\
\hline 189 & Very High & Very Low & High & Heavy & Little Low \\
\hline. & & & & & \\
\hline 217 & Very High & Very High & Low & Light & High \\
\hline 218 & Very High & Very High & Low & Moderate & High \\
\hline
\end{tabular}




\begin{tabular}{|l|l|l|l|l|l|}
\hline 219 & Very High & Very High & Low & Heavy & $\begin{array}{l}\text { Little } \\
\text { Medium }\end{array}$ \\
\hline 220 & Very High & Very High & Medium & Light & Very High \\
\hline 221 & Very High & Very High & Medium & Moderate & High \\
\hline 222 & Very High & Very High & Medium & Heavy & High \\
\hline 223 & Very High & Very High & High & Light & Very High \\
\hline 224 & Very High & Very High & High & Moderate & High \\
\hline 225 & Very High & Very High & High & Heavy & High \\
\hline
\end{tabular}

\section{RESULTS AND DISCUSSION}

The results corresponds to PV panel output, wind turbine output of first level fuzzy and number of units to be sold of second level fuzzy are elaborated in this section. The influence of temperature and humidity on PV panel output is shown in fig.7.

It is observed from the fig.7 that as the temperature increases PV panel power output increases up to moderate temperature of $25^{\circ} \mathrm{C}$ and then decreases. It clearly elucidates that the output power is maximum only when the temperature is moderate. Similarly, the PV panel output decreases with increase in humidity. Further, the influence of shading, irradiation and soiling on PV panel output is depicted in fig. 8 and 9 respectively.

From the fig.8, it is evident that PV panel output increases as shading decreases and vice versa. It is also found that as the irradiation increases, the PV panel output increases. Soiling has an adverse effect in PV panel power production and is very clear from fig.9 that as the soiling increases, the PV panel output decreases. The impact of wind direction and wind speed on output power is illustrated in fig. 10.

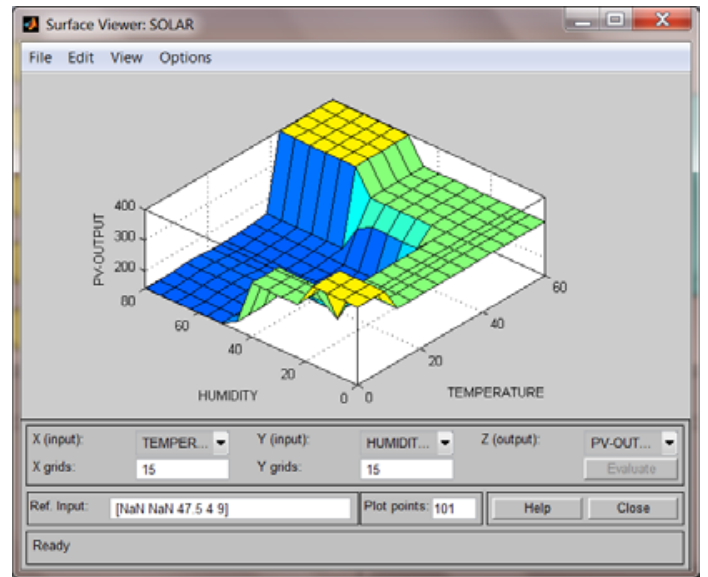

Fig.7. Plot of temperature and humidity Vs PV output

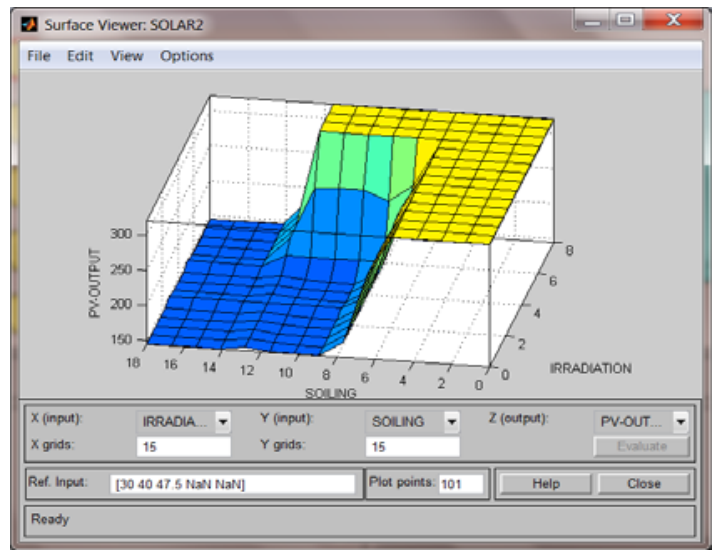

Fig. 9 Plot of Soiling and Irradiation Vs PV output

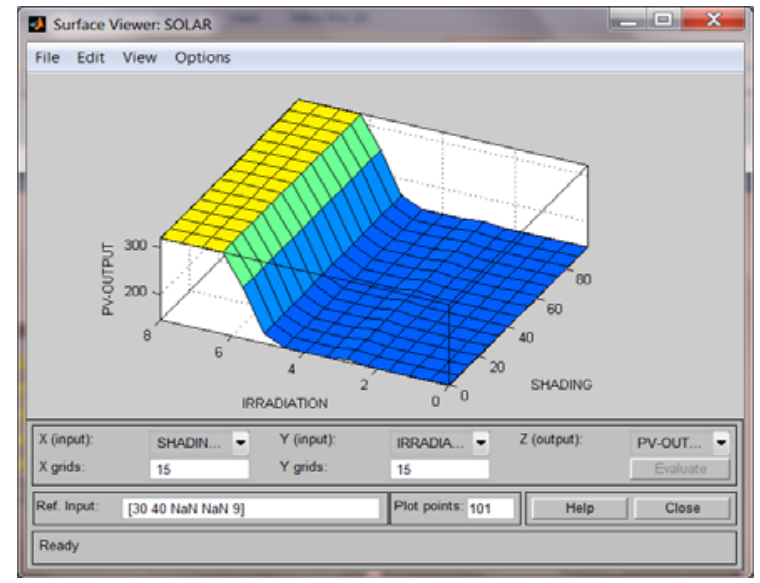

Fig.8. Plot of shading and irradiation Vs PV output

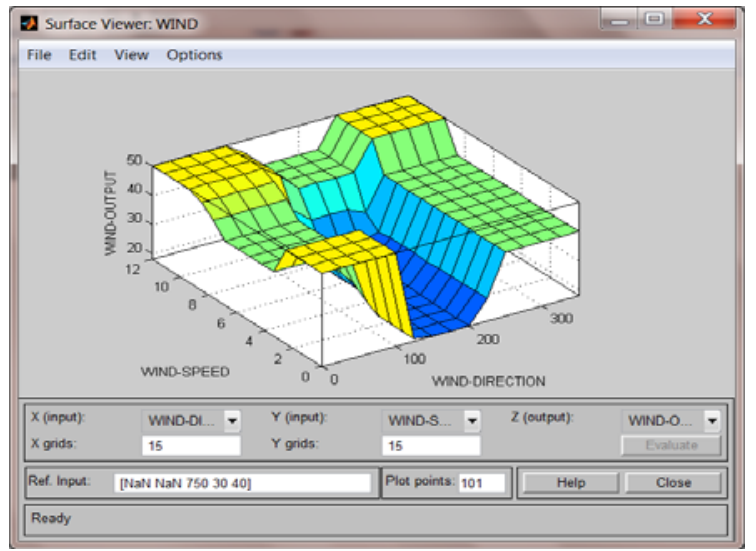

Fig.10 Plot of wind speed and wind direction Vs wind turbine output 


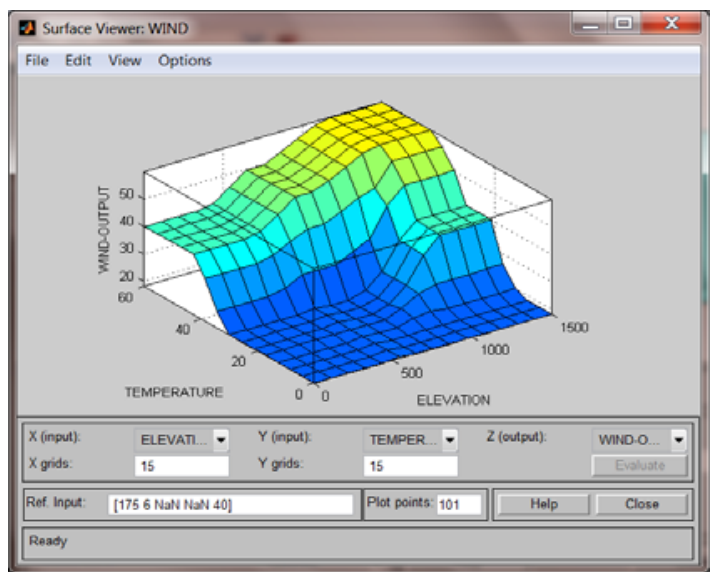

Fig.11 Plot of temperature and elevation Vs wind output

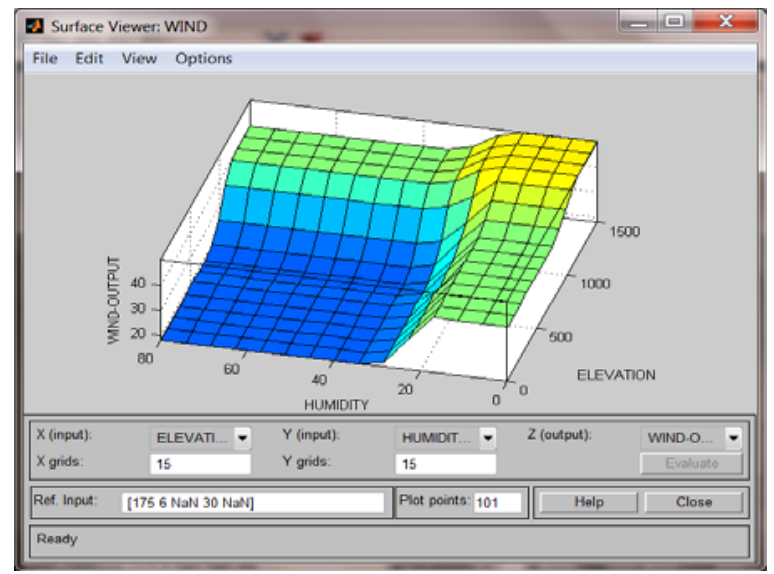

Fig.12 Plot of humidity and elevation Vs wind output

It is apparent from the figure that as wind direction is moderate, output power is found to be high. Also, it is found that as the wind speed increases, the output power increases. Further, the impact of elevation, temperature and relative humidity on output power is portrayed in fig. 11 and fig. 12 respectively.

From fig.11, it is clear that the output power is found to increase with increase in altitude. Similarly, the output power increases with increase in temperature. On the other hand, from fig. 12 it is evident that the output power is found to decrease with increase in relative humidity.

The influence of PV panel output, wind turbine output, battery SoC and connected load on number of units of energy to be sold is shown in fig. 13 and fig. 14 respectively.

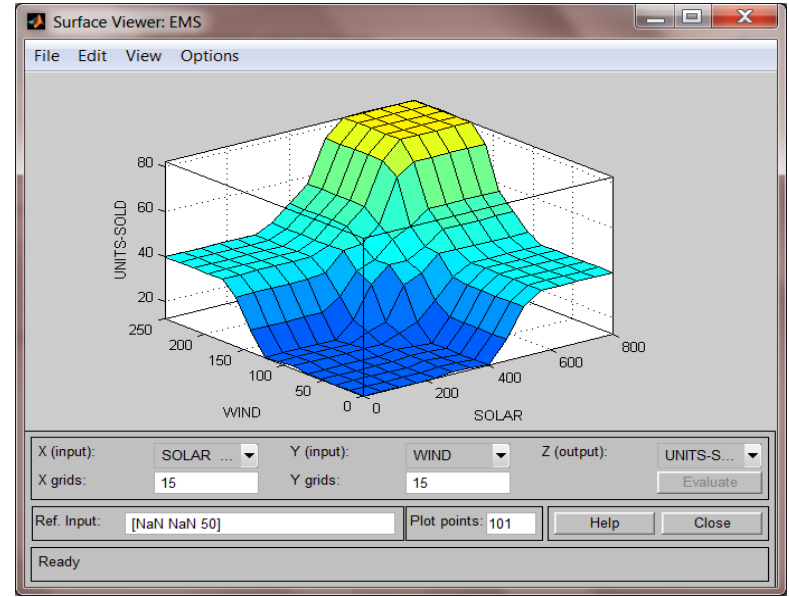

Fig.13 Plot of PV and wind power output Vs units sold

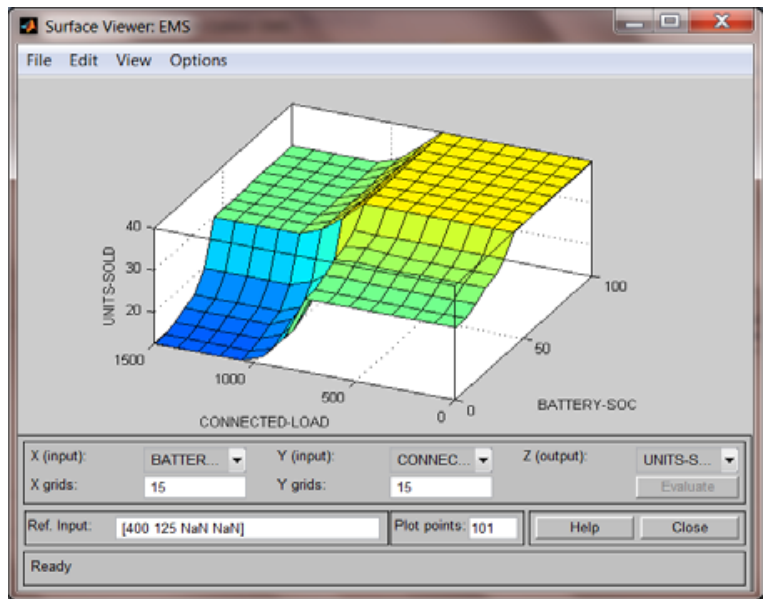

Fig.14 Plot of battery SoC and connected load Vs units sold

From fig. 13 and fig.14, it is evident that as PV panel output and wind turbine output increases, the number of units sold to the utility increases. As Battery SoC increases, number of units to be sold to utility increases. Similarly, the number of units to be sold is found to decrease with increase in connected load. Hence, it is concluded that the number of units to be sold to the utility increases with increase in PV panel output, wind turbine output, battery SoC and decrease in connected load.

\section{CONCLUSION}

Sustainable and reliable power production from renewable resources is mandate. Hence, a novel two level fuzzy based energy prediction system is proposed. The proposal considers the influencing parameters for both solar and wind energy based power production. Accordingly, the first level fuzzy based controller which is designed to produce maximum power from these resources. The total power generated from the hybrid system is compared with that of the total demand. If the demand is lesser, then excess power is used to charge the battery and hence, the State of Charge of the battery can be increased up to $95 \%$ using second level fuzzy logic controller. If the power is again excess, then it will be sold to the utility. The algorithm is implemented in Matlab. The results of proposed methodology exhibit its efficacy. 


\section{REFERENCES}

[1] Albert Martin Ruban, G. Mathew Rajasekaran, N. Rajeswari and J. Arokia Raj, 'Implementation of Energy Management System using Fuzzy Control to the Hybrid Power Generation System for DC Microgrid Applications', International Journal of Electrical Engineering, Volume 8, No. 4 (2015), pp. 341-354

[2] Albert Martin Ruban, G. Mathew Rajasekaran and R. Poongodi, 'Implementation of Energy Management System to PV-Wind-Diesel Hybrid Power Generation System for Smart Micro grid Applications', International Journal of Applied Engineering Research, Vol. 10, No.51 (2015), pp.277-283.

[3] Emad Maher Natsheh ,Abdel Razzak Natsheh and Alhussein Albarbar, 'Intelligent Controller for Managing Power Flow Within Standalone Hybrid Power Systems’, IET Science, Measurement \& Technology, Vol. 7, Issue: 4, (2013), pp.191 - 200.

[4] Sanaa Faquir, Ali Yahyaouy, Hamid Tairi, Jalal Sabor, 'A type-1 fuzzy logic algorithm to managethe flow of energy in a standalone PV/wind/battery hybrid system', IEEE, Intelligent Systems and Computer Vision (ISCV), (2015).

[5] Dariush Shahgoshtasbi and Mo M. Jamshidi, ‘A New Intelligent Neuro-Fuzzy Paradigm for Energy-Efficient Homes', IEEE Systems Journal, Vol. 8, No. 2, 664-673,June 2014

[6] Doris Sáez, Fernanda Ávila, Daniel Olivares, Claudio Cañizares, Luis Marín,' Fuzzy PredictionInterval Models for Forecasting Renewable Resources and Loads in Microgrids',IEEE Transactions on Smart Grid, Vol. 6, no. 2,(2015), pp.548-556.

[7] Felipe Valencia, Jorge Collado, Doris Sáez, and Luis G. Marín, 'Robust Energy Management System for a Microgrid Based on a Fuzzy Prediction Interval Model, IEEE Transactions on Smart Grid, Vol. 7, No. 3,(2016), pp.1486-1494.

[8] Saurabh S. Soman, Hamidreza Zareipour, Om Malik, Paras Mandal, 'A review of wind power and wind speed forecasting methods with different time horizons', IEEE, North American Power Symposium, (2010).

[9] Avisekh Lal, Ravitesh Kumar and Utkal Mehta,'Energy Dispatch Fuzzy Model in Hybrid Power System', International Energy Journal, (2014), pp. 133-142.

[10] B. Marion, J. Adelstein, K. Boyle H. Hayden, B. Hammond et al., 'Performance Parameters for Grid-Connected PV Systems', $31^{\text {st }}$ IEEE Photovoltaics Specialists Conference and Exhibition, pp:.1-6

[11] Diego Arcos-Aviles, Julio Pascual, Luis Marroyo, Pablo Sanchis and Francesc Guinjoan,' Fuzzy Logic- Based Energy Management System Design for Residential Grid-Connected Microgrids', IEEE Transactions on Smart Grid, Issue: 99, (2016).

[12] Mohammad RezaMaghami a,b,n, HashimHizam a,b, ChandimaGomes et al., 'Power loss due to soiling on solar panel: A review', Renewable and Sustainable Energy Reviews, Elsevier,(2016).

[13] Trishan Esram and Patrick L. Chapman,' Comparison of Photovoltaic Array Maximum Power Point Tracking Techniques', IEEE Transactions on Energy Conversion, Vol. 22, Issue. 2, (2007), pp.439- 449. 